\title{
Toward sustainable Li-ion batteries recycling: Green MOF as a molecular sieve for the selective separation of cobalt and nickel
}

\author{
Jędrzej Piątek, Tetyana M. Budnyak, Bruno V. M. Rodrigues, Robin Gueret, Erik Svensson Grape, Ale- \\ ksander Jaworski, A. Ken Inge and Adam Slabon*
}

Keywords: adsorption, metal-organic framework, battery recycling, nickel recovery, cobalt recovery

\begin{abstract}
The growing demand for Li-ions batteries (LIBs) has made their postconsumer recycling an imperative need towards the recovery of valuable metals, such as cobalt and nickel. Nevertheless, their recovery and separation from active cathode materials in LIBs, via an efficient and environmentally friendly process, have remained a challenge. In this work, we approach a simple and green method for the selective separation of nickel ions from mixed cobalt-nickel aqueous solutions under mild conditions. We discovered that the bioinspired microporous metal-organic framework (MOF), $\mathrm{Bi}_{2} \mathrm{O}\left(\mathrm{H}_{2} \mathrm{O}\right)_{2}\left(\mathrm{C}_{14} \mathrm{H}_{2} \mathrm{O}_{8}\right) \cdot \mathrm{nH}_{2} \mathrm{O}$ is a selective sorbent towards $\mathrm{Ni}(\mathrm{II})$ ions at $\mathrm{pH}$ 5-7, but does not adsorb $\mathrm{Co}$ (II) ions. According to the Freundlich isotherm, the adsorption capacity towards Ni(II) reached 100.9

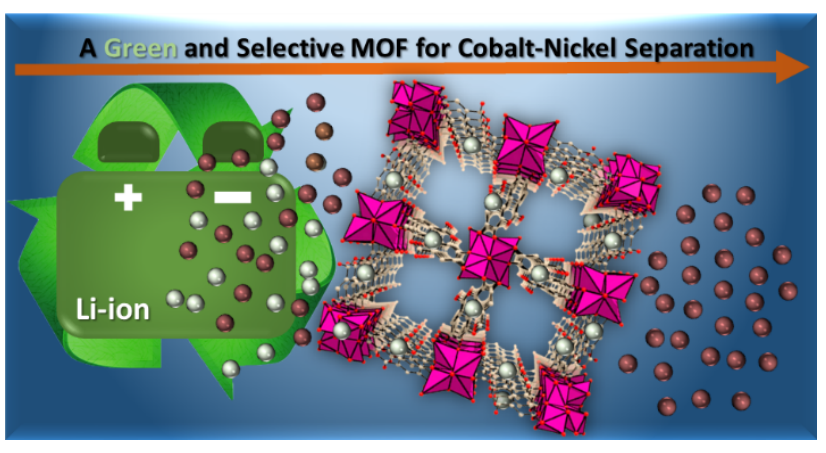
$\mathrm{mg} \cdot \mathrm{g}^{-1}$, while a near-zero adsorption capacity was found for $\mathrm{Co}(\mathrm{II})$ ions. $\mathrm{Ni}$ (II) removal from aqueous solutions was performed at mild conditions $\left(22^{\circ} \mathrm{C}\right.$ and $\left.\mathrm{pH} 5\right)$, with a high yield up to $96 \%$. Presence on $\mathrm{Ni}$ (II) ions adsorbed on the surface of the material has been proven by solid state ${ }^{1} \mathrm{H}$ nuclear magnetic resonance (NMR) spectroscopy. Finally, separation of Ni(II) from Co(II) from binary solutions was obtained with approximately $30 \%$ yield for $\mathrm{Ni}(\mathrm{II})$, with a near-zero adsorption of $\mathrm{Co}$ (II), which has been demonstrated by UV-Vis spectroscopy. These results offer a green pathway toward the recycling and separation of valuable metals from cobaltcontaining LIBs, while providing a sustainable route for waste valorization in a circular economy.
\end{abstract}

\section{INTRODUCTION}

Cobalt and nickel are one of the most common components of cathode materials in lithium-ion batteries (LIBs) in the form of lithium-metal oxides. These metals are found together in lithium nickel manganese cobalt oxide (NMC) or lithium nickel cobalt aluminium oxide (NCA) cathodes. ${ }^{1,2}$ The European Commission predicts that the demand for cobalt supply related to LIBs production will increase 5 times in 2030 and 15 times in 2050, comparatively to the current supply to EU countries. Cobalt has already been classified as a critical raw material (CRM), while nickel is under observation due to rising requisition of LIBs for energy storage and electric vehicle batteries. ${ }^{3}$ Depletion of natural deposits of cobalt and nickel may result in a global shortage for future prospects. Hence, the recovery of these elements is currently of high importance. The majority of electronic wastes containing many precious elements is however not recycled, while the permeation of toxic elements may have direct consequences for the natural environment. ${ }^{4,5}$

Sustainable methods for the recycling of LIBs have received recently high interest. However, conventional industrial processes still implement non-green methods, i.e. high temperature processes and toxic chemicals, and do not ensure the same purity grade as the starting materials for synthesis of active electrode materials. In addition, these processes often leads to the formation of waste byproducts, which in turn may present hazardous effects to the natural environment. ${ }^{6,7}$ After proper mechanical processing, e.g. discharging and dismantling, NMC and NCA cathode materials are usually treated with mineral acids and separated from the solid fraction by filtration. The leachates obtained in these processes comprise mixtures of cobalt, nickel and manganese or aluminium salts. The separation of these ions is generally performed via hydrometallurgical methods, like solvent extraction ${ }^{8-10}$, precipitation $^{11,12}$ and ion exchange. ${ }^{13,14}$ These techniques usually implement highly toxic organic solvents, while operating at harsh conditions and requiring additional separation steps. In sum, the current existing methods in industrial processes do not follow the principles of green chemistry, while being time-consuming. ${ }^{15,16}$

Adsorption is a highly efficient surface process to remove target components from solutions. This method predominates over the aforementioned alternatives due to its capacity to operate under mild conditions, therefore minimizing the implementation of bulk chemicals. ${ }^{17}$ This method can be applied for the removal of metal ions ${ }^{18}$, dyes $^{19}$ and organic compounds ${ }^{20}$ from wastewaters, with high effectiveness even for very low concentrations. Adsorption has been also implemented as a step process in cobalt ions recovery from LIBs. ${ }^{21}$ Although many different sorbents have been applied for cobalt and nickel recovery $^{22-25}$, the most part fail in terms of selectivity towards any of them. Thus, these sorbents still need to undergo additional processes in order to separate the metals ions, whenever this is possible. In this context, the development 
of sustainable methods for the selective separation of metal ions from water solutions has become crucial and urgent.

Metal-organic frameworks (MOFs) are hybrid porous materials comprised of metal ions or clusters and organic ligands. Over the past two decades, these materials gained much scientific interest due to their broad range of application, i.e. catalysis, hydrogen storage, carbon capture, semiconductors, drug delivery systems and biological imaging and sensing. ${ }^{26-33}$ As sorbents, they have been investigated for the adsorption of dyes ${ }^{34}, \mathrm{H}_{2}{ }^{35}, \mathrm{O}_{2}{ }^{36}$ and $\mathrm{CO}_{2}{ }^{37}$ gases, as well as heavy metals ${ }^{38}$ from aqueous solutions. Recently, we have reported on the green synthesis of a bismuth ellagate MOF, by using non-hazardous chemicals in a simple synthesis process under ambient conditions. Besides a high chemical stability, this MOF presents interesting physico-chemical and surface properties, which place it as a material with a great potential towards heavy metal ion recycling. ${ }^{39}$

In this work, bismuth ellagate $\mathrm{Bi}_{2} \mathrm{O}\left(\mathrm{H}_{2} \mathrm{O}\right)_{2}\left(\mathrm{C}_{14} \mathrm{H}_{2} \mathrm{O}_{8}\right) \cdot \mathrm{nH}_{2} \mathrm{O}$ MOF (SU-101) has been investigated as a selective agent for $\mathrm{Ni}(\mathrm{II})$ removal from mixed cobalt-nickel aqueous solutions. Ni(II) adsorption kinetics have been determined using pseudo-first and pseudo-second order reaction equations. The possibility of intraparticle diffusion has been verified, while Langmuir, Freundlich and Temkin models have been applied to investigate the isotherm model of $\mathrm{Ni}$ (II) adsorption. This green MOF realizes as such Co-Ni separation at room temperature, yielding the opportunity to recover cobalt as the most important metal from cathode materials in LIBs.

\section{EXPERIMENTAL SECTION}

\section{Materials}

1-nitroso-2-naphthol-3,6-disulfonic acid sodium salt hydrate (pure, indicator grade), sodium tetraborate (98\%), ellagic acid (97\%), acetic acid (99.7\%), 4-(2'-pyridylazo)resorcinol (97+\%, ACS) and dimethylglyoxime (99+\%) were obtained from Acros Organics, Belgium. Nickel(II) nitrate hexahydrate (98\%), cobalt(II) nitrate hexahydrate (98\%) and bismuth acetate (99\%) were obtained from Alfa Aesar, USA. Ethanol absolute, sodium chloride (min. $99.8 \%$ ), sodium acetate $(99.8 \%$ ), hydrochloric acid (37\%), nitric acid (65\%) and ammonia (25\%) were obtained from VWR, USA. Sodium hydroxide (98-100.5\%) and toluene $(\geq 99.7 \%)$ were obtained from Honeywell, USA. Iodine solution $(0.05 \mathrm{M})$ was obtained from Merck, USA.

\section{Methods}

Synthesis procedure and characterization of $\mathrm{Bi}_{2} \mathrm{O}\left(\mathrm{H}_{2} \mathrm{O}\right)_{2}\left(\mathrm{C}_{14} \mathrm{H}_{2} \mathrm{O}_{8}\right) \cdot n \mathrm{H}_{2} \mathrm{O}(\mathrm{SU}-101)$ MOF are described in detail in a previous work. ${ }^{39}$ Briefly, ellagic acid and bismuth acetate were added to $6 \%$ acetic acid mixture with water and stirred at room temperature for $48 \mathrm{~h}$. Next, the suspension was centrifuged at $8000 \mathrm{rpm}$ for $10 \mathrm{~min}$ and dried overnight in a circulating oven $\left(60{ }^{\circ} \mathrm{C}\right)$. A fine powder of bismuth ellagate metal-organic was obtained with a yield of $76 \%$. The $\mathrm{pH}$ of point zero charge $\left(\mathrm{pH}_{\mathrm{pzc}}\right)$ for $\mathrm{SU}-101$ has been investigated via the $\mathrm{pH}$ drift method, using $0.01 \mathrm{M} \mathrm{NaCl}$ solutions with $\mathrm{pH}$ ranging from 2 to 12 . To $5 \mathrm{~mL}$ of each solution, $20 \mathrm{mg}$ of the SU101 was suspended, shaken for $24 \mathrm{~h}$, filtered, after which the final $\mathrm{pH}$ was measured.

Batch adsorption experiments were conducted by suspending $0.1 \mathrm{~g}$ of SU-101 in $25 \mathrm{~mL}$ of cobalt(II) nitrate or nickel(II) nitrate solutions in $100 \mathrm{~mL}$ flasks, which were shaken for a given time in a Heidolph Unimax 1010 incubating shaker (Germany), at $180 \mathrm{rpm}$ and $22{ }^{\circ} \mathrm{C}$. The $\mathrm{pH}$ influence on adsorption was evaluated by preparing solutions containing $50 \mathrm{mg} \cdot \mathrm{L}^{-1}$ of $\mathrm{Co}(\mathrm{II})$ or
$\mathrm{Ni}(\mathrm{II})$ and adjusting the $\mathrm{pH}$ from 2 to 8 with $0.01 \mathrm{M} \mathrm{HNO}_{3}$ and $0.01 \mathrm{M} \mathrm{NH}_{4} \mathrm{OH}$ solutions. Isotherms have been evaluated with solutions of initial concentration of $2-80 \mathrm{mg} \cdot \mathrm{L}^{-1}$ at $\mathrm{pH} 2.0$ and 5.0 for $\mathrm{Co}(\mathrm{II})$ and concentration of $2-520 \mathrm{mg} \cdot \mathrm{L}^{-1}$ at $\mathrm{pH} 5.0$ and 7.0 for $\mathrm{Ni}$ (II) ions. The equilibrium time needed for the adsorption was investigated by suspending the sorbent in 50 and 100 $\mathrm{mg} \cdot \mathrm{L}^{-1} \mathrm{Co}(\mathrm{II})$ or $\mathrm{Ni}(\mathrm{II})$ solutions for 0.25 to $24 \mathrm{~h}$. The final concentration of metal ions was determined by methods described by Marchenko ${ }^{40}$, using a UV-3100PC spectrophotometer (VWR, USA). Absorbance was measured by the formation of $\mathrm{Co}$ (II) complexes with 4-(2'-pyridylazo)resorcinol (at $500 \mathrm{~nm}$ ) and $\mathrm{Ni}(\mathrm{II})$ complexes with dimethylglyoxime (at $470 \mathrm{~nm}$ ). The adsorption capacity $\left(\mathrm{q}_{\mathrm{eq}}\right)$ was calculated using the Equation (1):

$q_{e q}=\frac{\left(c_{0}-c_{e q}\right) V}{m}$

where $C_{0}$ is the initial metal concentration $\left(\mathrm{mg} \cdot \mathrm{L}^{-1}\right), C_{e q}$ is the equilibrium metal concentration $\left(\mathrm{mg} \cdot \mathrm{L}^{-1}\right), V$ is the sample volume (L) and $m$ is the sorbent mass (g). To investigate the mechanism behind the adsorption of $\mathrm{Ni}$ (II) ions, three isotherm models were determined: Langmuir, Freundlich and Temkin. In Langmuir model, the adsorption occurs on a homogenous surface layer (monolayer), in which adsorbed components do not interact with each other. The Langmuir model can be expressed as follows:

$\frac{C_{e q}}{q_{e q}}=\frac{C_{e q}}{q_{0}}+\frac{1}{K_{L} q_{0}}$

where $C_{e q}$ is the equilibrium concentration of metal ions $\left(\mathrm{mg} \cdot \mathrm{L}^{-1}\right), q_{e q}$ is the amount of the adsorbed ions $\left(\mathrm{mg} \cdot \mathrm{g}^{-1}\right), q_{0}$ is the sorption capacity $\left(\mathrm{mg} \cdot \mathrm{g}^{-1}\right)$ and $K_{L}$ is the equilibrium constant $\left(\mathrm{L} \cdot \mathrm{mg}^{-1}\right)$. Langmuir isotherm can be also expressed with a dimensionless separating factor $R_{L}$ :

$R_{L}=\frac{1}{1+K_{L} C_{0}}$

where $C_{0}$ is the initial concentration of adsorbate $\left(\mathrm{mg} \cdot \mathrm{g}^{-1}\right)$.

Freundlich model describes multilayer adsorptions, and can be expressed as:

$\log q_{e q}=\log K_{F}+\frac{1}{n} \log C_{e q}$

where $K_{F}$ and $n$ are the Freundlich constants of sorption capacity $\left(\mathrm{L} \cdot \mathrm{mg}^{-1}\right)$ and sorption intensity respectively.

Temkin model has been calculated with following equation:

$C_{S}=\frac{R T}{b_{T}} \ln K_{T}+\frac{R T}{b_{T}} \ln C_{e q}$

where $C_{S} i$ s the concentration of metal in solid phase $\left(\mathrm{mol} \cdot \mathrm{g}^{-1}\right)$, $K_{T}$ is the model constant $\left(\mathrm{L}^{-\mathrm{g}^{-1}}\right), R$ is the gas constant $(8.314$ $\left.\mathrm{J} \cdot \mathrm{mol}^{-1} \cdot \mathrm{K}^{-1}\right), T$ is the absolute temperature $(\mathrm{K}), b_{T}$ is the heat of adsorption $\left(\mathrm{J} \cdot \mathrm{mol}^{-1}\right)$ and $C_{e q}$ is the equilibrium metal concentration in aqueous phase $\left(\mathrm{mol} \cdot \mathrm{L}^{-1}\right){ }^{23,41}$

Kinetics of Ni(II) adsorption has been checked using pseudo-first and pseudo-second order models. The intraparticle diffusion of the adsorption has been also verified. Pseudo-first and pseudo-second order models were calculated using the following equations.

Pseudo-first order equation:

$\log \left(q_{e q}-q_{t}\right) \log q_{e q}-\frac{k_{1} t}{2.303}$

Pseudo-second order equation:

$\frac{t}{q_{t}}=\frac{1}{k_{2} q_{e q}^{2}}+\frac{t}{q_{e q}}$ 
where $q_{e q}$ and $q_{t}$ are the adsorption capacities $\left(\mathrm{mg} \cdot \mathrm{g}^{-1}\right)$ at equilibrium and at any instant time of $t$ respectively, $k_{l}$ is the rate constant of the pseudo-first order reaction $\left(1 \cdot \mathrm{min}^{-1}\right)$ and $k_{2}$ is the rate constant of pseudo-second order reaction $\left(\mathrm{g} \cdot \mathrm{mg}^{-1} \cdot \mathrm{min}^{-1}\right) \cdot{ }^{23,42}$

The Weber and Morris equation has been applied to examine whether intraparticle diffusion occurs:

$$
q_{t}=K_{I P D} t^{0.5}+C
$$

where $K_{I P D}$ is the intraparticle diffusion rate $\left(\mathrm{mg} \cdot \mathrm{g}^{-1} \cdot \mathrm{min}^{-0.5}\right)$ and $C$ is a constant. ${ }^{23,43}$

The separation of $\mathrm{Ni}(\mathrm{II})$ from $\mathrm{Co}(\mathrm{II})$ via adsorption was evaluated by stirring mixed cobalt-nickel solutions, which contained 4 and $10 \mathrm{mg} \cdot \mathrm{L}^{-1}$ of each metal, for $24 \mathrm{~h}$ with $0.1 \mathrm{~g}$ of SU-101 sorbent at $22^{\circ} \mathrm{C}$. After that, solutions were filtered and the final concentration of $\mathrm{Ni}$ (II) and $\mathrm{Co}$ (II) was determined by placing $2 \mathrm{~mL}$ of samples in $25 \mathrm{~mL}$ flasks, to which $5 \mathrm{~mL}$ of 0.5 $\mathrm{mmol} \cdot \mathrm{L}^{-}$1-nitroso-2-naphthol-3,6-disulfonic acid sodium salt (nitroso-R salt) and $7.5 \mathrm{~mL}$ of acetate buffer $(\mathrm{pH} 5.5)$ were added and filled with water up to $25 \mathrm{~mL}$. Then UV-Vis spectra of the samples were collected from 800 to $350 \mathrm{~nm}$ using an UVVis spectrophotometer. Simultaneous determination of these two metal ions in this study was based on the method proposed by Zhou et al. ${ }^{44}$.

The ${ }^{1} \mathrm{H}$ magic angle spinning (MAS) nuclear magnetic resonance (NMR) experiments were performed at the magnetic field $B_{0}=14.1 \mathrm{~T}$ (Larmor frequency of $600.12 \mathrm{MHz}$ ) and MAS rate $v_{\mathrm{r}}=60.00 \mathrm{kHz}$ on a Bruker Avance-III spectrometer equipped with $1.3 \mathrm{~mm}$ MAS probehead. The ${ }^{1} \mathrm{H}$ acquisitions involved rotor-synchronized, double-adiabatic spin-echo sequence with $90^{\circ} 1.25 \mu$ s excitation pulse followed by two $50.0 \mu \mathrm{s} \tanh / \tan$ high-power adiabatic pulses (SHAPs) with 5 $\mathrm{MHz}$ frequency sweep. ${ }^{45,46}$ All pulses operated at the nutation frequency $v_{\text {nut }}=200 \mathrm{kHz} .128$ signal transients with $5 \mathrm{~s}$ relaxation delay were accumulated for each spectrum. Shifts were referenced with respect to neat tetramethylsilane (TMS).

\section{RESULTS AND DISCUSSION}

In a previous work, it has been found that $\mathrm{SU}-101$ is chemically stable in the $\mathrm{pH}$ range from 2 to $14 .{ }^{39} \mathrm{The}_{\mathrm{pH}}$ reveals at which $\mathrm{pH}$ the surface of the material is neutral, i.e., same number of positive and negative charges. When the $\mathrm{pH}$ is below the $\mathrm{pH}_{\mathrm{pzc}}$, the material's surface is positively charged, whereas if the $\mathrm{pH}$ is above $\mathrm{pH}_{\mathrm{pzc}}$ the surface is negatively charged. ${ }^{47}$ The $\mathrm{pH}$ of point zero charge for SU-101 was found to be 2.29 (Figure S1 in Electronic Supplementary Information, ESI), which means that $\mathrm{pH}$ values above $\mathrm{pH}_{\mathrm{pzc}}$ favour the adsorption of positively charged metal ions. Initially, batch adsorption experiments with respect to $\mathrm{pH}$ were conducted (Figure 1). For $\mathrm{Co}$ (II) ions, the highest sorption capacity was obtained at $\mathrm{pH} 2.0$ (6.52 $\mathrm{mg} \cdot \mathrm{g}^{-1}, 36.5 \%$ efficiency), whilst for nickel(II) ions the highest capacity was found at $\mathrm{pH} 8.0$ (14.6 $\left.\mathrm{mg} \cdot \mathrm{g}^{-1}, 80.5 \%\right)$. However the most interesting results were obtained at $\mathrm{pH} 5.0$, where $\mathrm{Ni}$ (II) sorption starts to equilibrate, reaching $14.2 \mathrm{mg} \cdot \mathrm{g}^{-1}$ (78.9\% efficiency), while $\mathrm{Co}(\mathrm{II})$ adsorption is near-zero $\left(0.08 \mathrm{mg} \cdot \mathrm{g}^{-1}, 0.4 \%\right.$ efficiency $)$. Due to the selectivity for $\mathrm{Ni}$ (II) sorption over $\mathrm{Co}$ (II) ions, further studies at pH 5.0 were carried out in mixed cobalt-nickel solutions, in order to verify the selectivity of SU-101 towards Ni(II). Additional experiments at $\mathrm{pH} 2.0$ for $\mathrm{Co}$ (II) and 7.0 for $\mathrm{Ni}$ (II) were also carried out for the isolated ions.

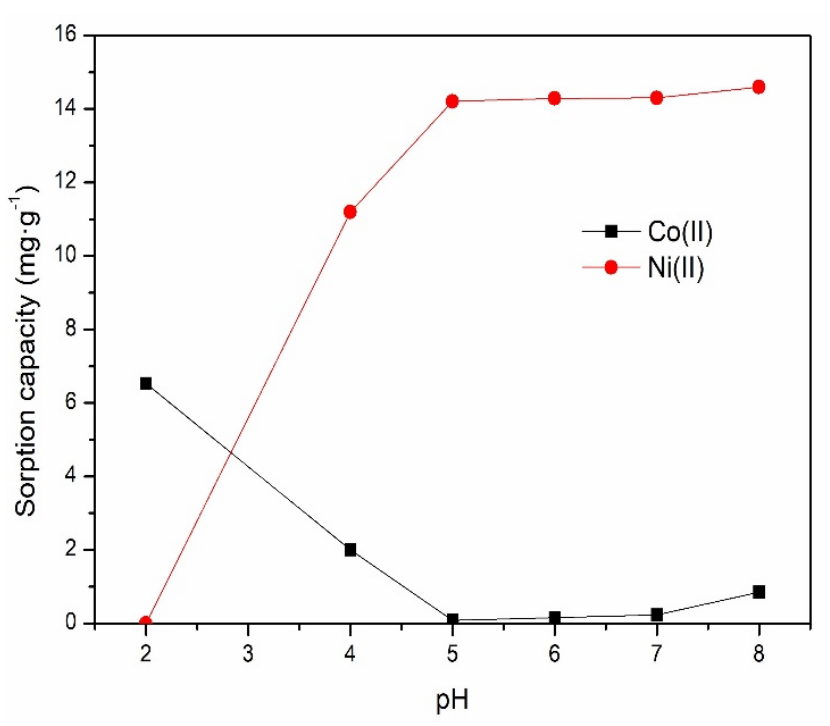

Figure 1. Effect of initial $\mathrm{pH}$ on adsorption of cobalt and nickel ions.

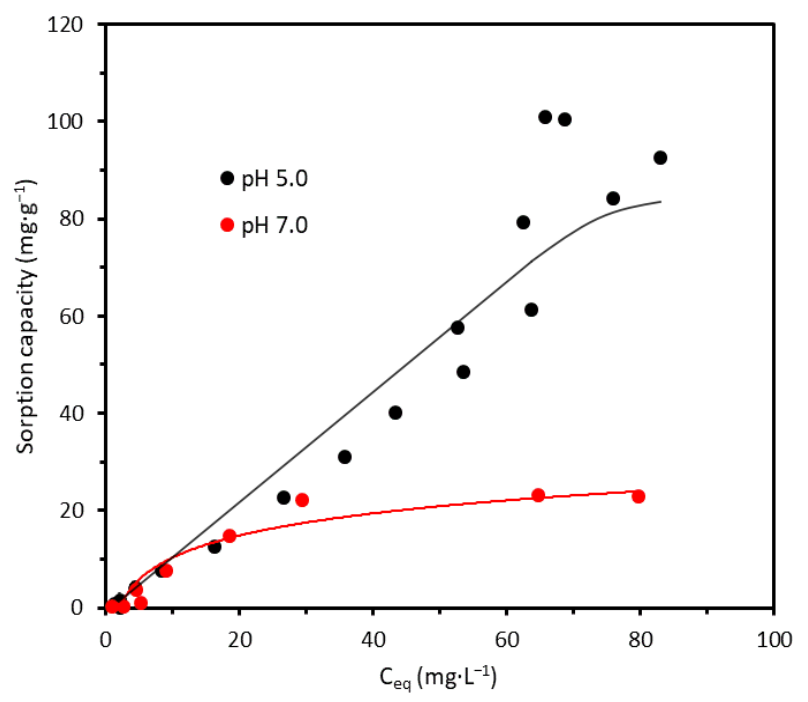

Figure 2. Adsorption isotherms of nickel ions on SU-101.

Isotherms for $\mathrm{Co}(\mathrm{II})$ adsorption were measured at $\mathrm{pH}$ 2.0 and 5.0 , at $22^{\circ} \mathrm{C}$, for $3 \mathrm{~h}$ (Figure S2 in ESI). Poor sorption capacities at both $\mathrm{pH}$ values indicate that SU-101 is not suitable to remove $\mathrm{Co}$ (II) ions from aqueous solutions. Conversely, a high sorption capacity of $100.9 \mathrm{mg} \cdot \mathrm{g}^{-1}(87.3 \%$ efficiency) was found for $\mathrm{Ni}(\mathrm{II})$ at $\mathrm{pH} 5.0$; at $\mathrm{pH} 7.0$, the maximal capacity decreased to $23.3 \mathrm{mg} \cdot \mathrm{g}^{-1}$ after $3 \mathrm{~h}$ (Figure 2 ). In literature, one can find numerous reports on sorbents for Ni(II) ions with higher maximal capacity, e.g. modified silica $\left(172.4 \mathrm{mg} \cdot \mathrm{g}^{-1}\right)^{23}$, activated carbon $\left(140.85 \mathrm{mg} \cdot \mathrm{g}^{-1}\right)^{48}$ or algae $\left(181.2 \mathrm{mg} \cdot \mathrm{g}^{-1}\right)^{49}$. Nevertheless, SU-101 demonstrates a notable selectivity towards $\mathrm{Ni}$ (II) ions over $\mathrm{Co}$ (II) ions, while other reported sorbents usually adsorb indistinctly both metal ions. Isotherm models have been calculated for $\mathrm{Ni}$ (II) adsorption at $\mathrm{pH}$ 5.0, and the parameters are shown in Table 1 and Figures S3 - S5 (in ESI). The Freundlich isotherm model was found to be the most suitable based on the experimental data, with the highest correlation coefficient $\left(R^{2}=0.988\right)$. The Freundlich model assumes that the adsorption mechanism occurs on a heterogeneous surface of a sorbent, with possible interactions between adsorbed ions or molecules. $^{41}$ 


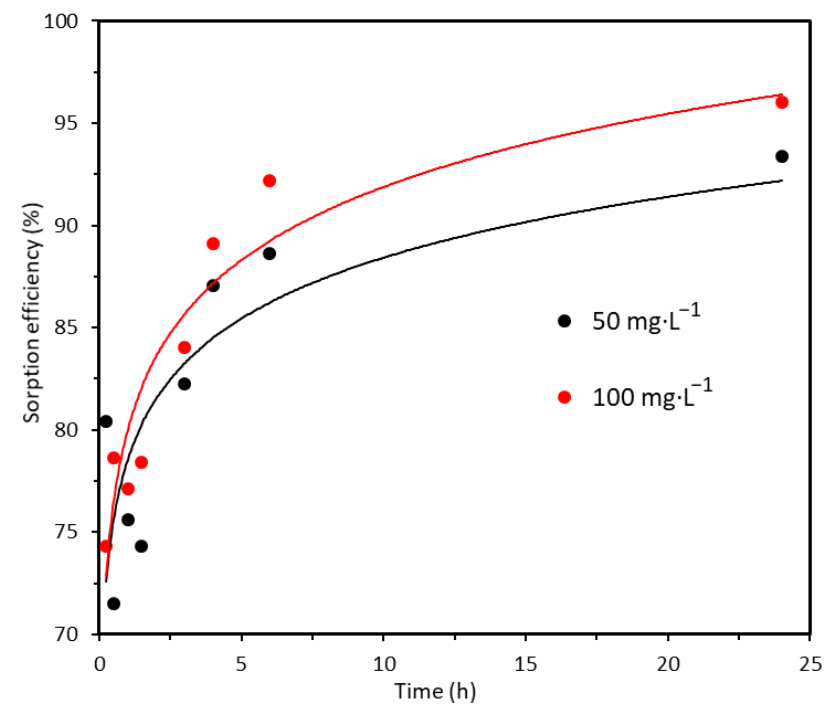

Figure 3. Adsorption kinetics of nickel ions on SU-101.

The study on the kinetics for Co(II) adsorption was performed at $\mathrm{pH} 2.0$ due to the highest probability to reach an equilibrium (Figure S6 in ESI). Nevertheless, the low sorption capacity $\left(0.53 \mathrm{mg} \cdot \mathrm{g}^{-1}, 3.1 \%\right.$ efficiency) obtained experimentally indicates that SU-101 is not suitable for the adsorption of these ions. The kinetics for $\mathrm{Ni}(\mathrm{II})$ adsorption was investigated with initial concentrations of 50 and $100 \mathrm{mg} \cdot \mathrm{L}^{-1}$, at pH 5.0 (Figure 3). The adsorption of nickel ions by SU-101 is a rapid and efficient process, even after $15 \mathrm{~min}$. The highest efficiency was reached after $24 \mathrm{~h}$ of shaking ( 93.3 and $96.0 \%$ for 50 and 100 $\mathrm{mg} \cdot \mathrm{L}^{-1}$ respectively), although it can be observed that the curves reach an equilibrium after $4-6 \mathrm{~h}$ of the process $(87-92 \%$ removal efficiency in both cases). The parameters for all kinetic models can be found in Table 2. A pseudo-first order model was constructed by fitting the experimental data from the slope and intercept of the $\log \left(q_{e q}-q_{t}\right)$ vs $t$ plot (Figure S7 in ESI). This model was found to be not suitable for Ni(II) adsorption, because the calculated equilibrium capacities in both cases did not match the experimental values, while also having a low correlation coefficient. Instead, a pseudo-second order model was constructed by plotting $t / q_{t}$ vs $t$ (Figure 4 ). It was found that the calculated values of $q_{e q}$ were similar to the ones obtained experimentally and the correlation coefficient in both cases was also high $(\sim 1.0)$, revealing the pseudo-second order reaction model as the most suitable for the adsorption of $\mathrm{Ni}(\mathrm{II})$ on SU-101. This result also shows that chemisorption is the main mechanism behind $\mathrm{Ni}(\mathrm{II})$ adsorption. ${ }^{42}$ The plot $q_{t}$ vs time $\left(t^{0.5}\right)$ is nonlinear in both cases, and it indicates that strong interactions and boundary layer diffusion may control the rate of adsorption (Figure S8 in ESI).

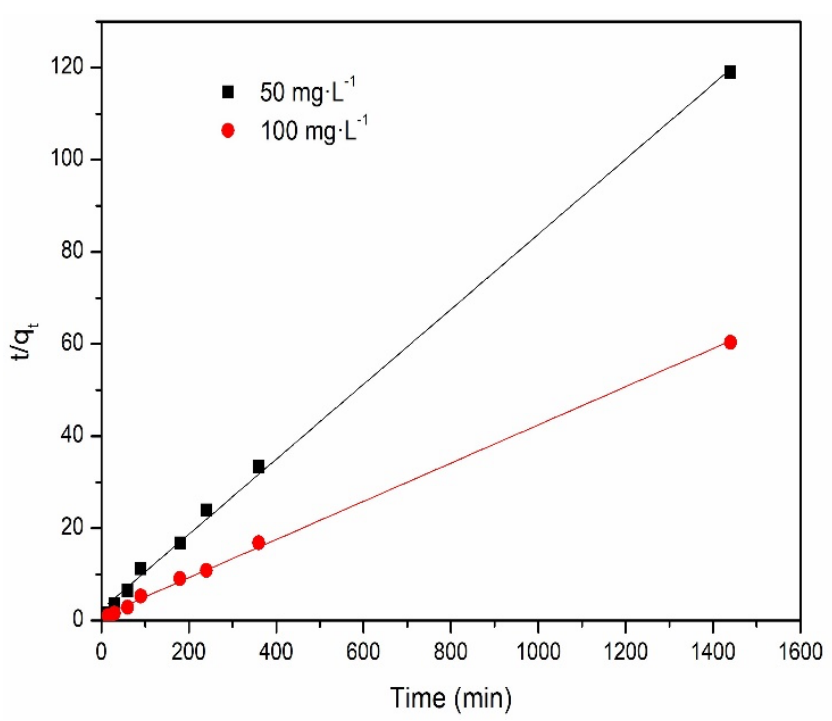

Figure 4. Pseudo-second order plot of Ni(II) adsorption.

Table 1. Langmuir, Freundlich and Temkin isotherm models parameters of $\mathrm{Ni}(\mathrm{II})$ adsorption at $\mathrm{pH}$ 5.0.

\begin{tabular}{ccc}
\hline Isotherm model & Parameter & Result \\
\hline \multirow{3}{*}{ Langmuir } & $q_{0}\left(\mathrm{mg}^{-1} \mathrm{~g}^{-1}\right.$ & 116.29 \\
& $K_{L}\left(\mathrm{~L} \cdot \mathrm{mg}^{-1}\right)$ & 0.0058 \\
& $R_{L}$ & 0.526 \\
& $R^{2}$ & 0.548 \\
\hline \multirow{3}{*}{ Freundlich } & $K_{F}\left(\mathrm{~L} \cdot \mathrm{mg}^{-1}\right)$ & 1.833 \\
& $n$ & 0.852 \\
& $R^{2}$ & 0.988 \\
\hline \multirow{3}{*}{ Temkin } & $b_{T}\left(\mathrm{~J} \cdot \mathrm{mol}^{-1}\right)$ & $80.192 \cdot 10^{3}$ \\
& $K_{T}\left(\mathrm{~J} \cdot \mathrm{mol}^{-1}\right)$ & $3.049 \cdot 10^{25}$ \\
& $R^{2}$ & 0.713
\end{tabular}

Table 2. Kinetic parameters of Ni(II) adsorption on SU101.

\begin{tabular}{|c|c|c|c|}
\hline \multirow{2}{*}{ Kinetic model } & \multirow{2}{*}{ Parameter } & \multicolumn{2}{|c|}{ Results } \\
\hline & & 50 ppm & $100 \mathrm{ppm}$ \\
\hline \multirow{4}{*}{$\begin{array}{l}\text { Pseudo-first } \\
\text { order }\end{array}$} & $q_{\text {eq, exp }}\left(m g \cdot g^{-1}\right)$ & 12.11 & 23.85 \\
\hline & $\mathrm{q}_{\mathrm{eq}, \mathrm{cal}}\left(\mathrm{mg} \cdot \mathrm{g}^{-1}\right)$ & 2.71 & 4.88 \\
\hline & $\mathrm{k}_{1}\left(1 \cdot \mathrm{min}^{-1}\right)$ & 0.048 & 0.072 \\
\hline & $\mathrm{R}^{2}$ & 0.515 & 0.615 \\
\hline \multirow{4}{*}{$\begin{array}{c}\text { Pseudo-second } \\
\text { order }\end{array}$} & $q_{\text {eq, exp }}\left(m g \cdot g^{-1}\right)$ & 12.11 & 23.85 \\
\hline & $\mathrm{q}_{\mathrm{eq}, \text { cal }}\left(\mathrm{mg} \cdot \mathrm{g}^{-1}\right)$ & 12.28 & 24.09 \\
\hline & $\mathrm{k}_{2}\left(\mathrm{~g} \cdot \mathrm{mg}^{-1} \cdot \mathrm{min}^{-1}\right)$ & $2.73 \cdot 10^{-3}$ & $1.74 \cdot 10^{-3}$ \\
\hline & $R^{2}$ & 0.998 & 0.999 \\
\hline \multirow{3}{*}{$\begin{array}{l}\text { Intraparticle } \\
\text { diffusion }\end{array}$} & $\mathrm{K}_{\mathrm{IPD}}\left(\mathrm{mg} \cdot \mathrm{g}^{-1} \cdot \mathrm{min}^{-0.5}\right)$ & 0.104 & 0.212 \\
\hline & $\mathrm{C}$ & 8.366 & 16.78 \\
\hline & $\mathrm{R}^{2}$ & 0.667 & 0.581 \\
\hline
\end{tabular}




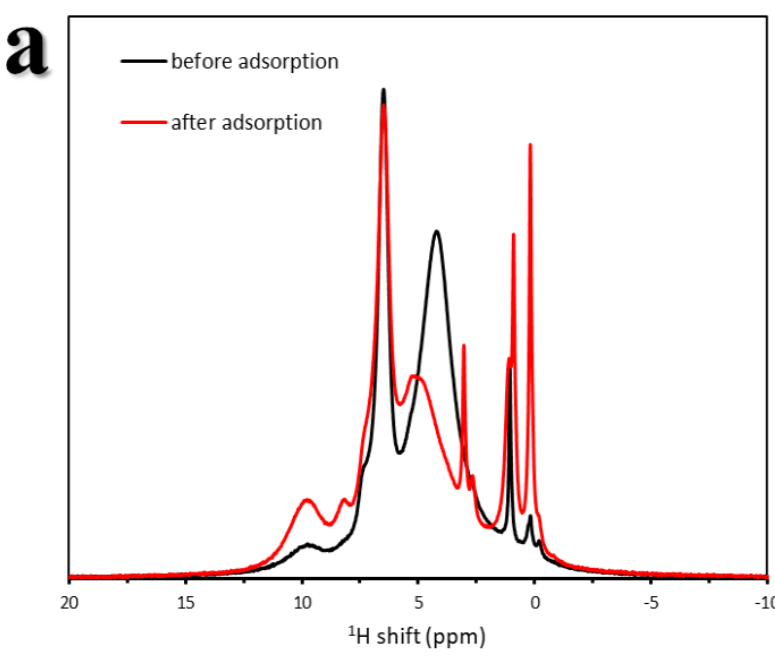

b

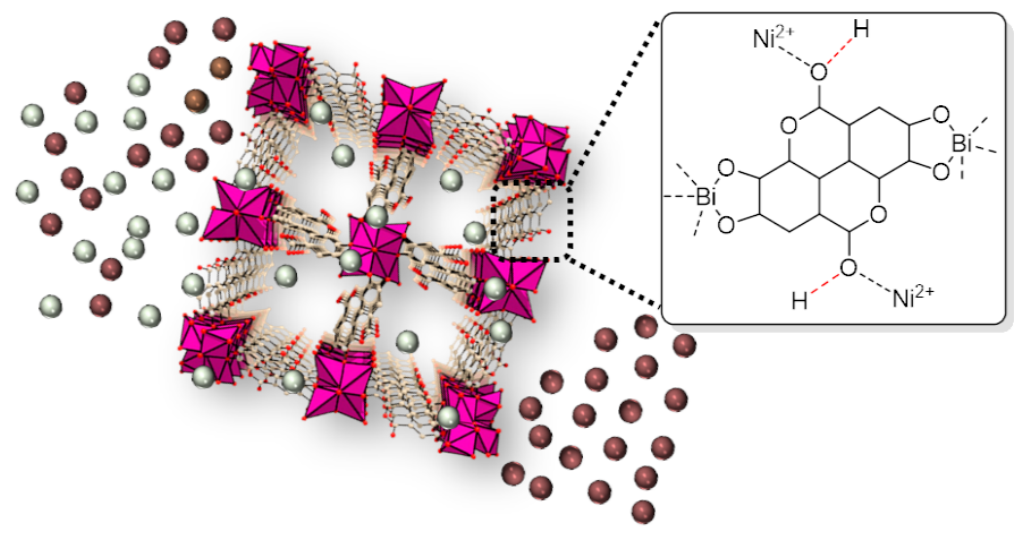

Figure 5. (a) ${ }^{1} \mathrm{H}$ MAS NMR spectra of SU-101 before (black) and after (red) Ni ions adsorption. The data were collected at $14.1 \mathrm{~T}$ and $60.00 \mathrm{kHz}$ MAS rate. (b) proposed mechanism for Ni(II) adsorption on SU-101 from mixed nickel-cobalt solution.

In Figure 5a, ${ }^{1} \mathrm{H}$ MAS NMR spectra collected from SU-101 samples before and after adsorption are presented. In the spectrum of as-synthesized sample (black trace), ${ }^{1} \mathrm{H}$ signals from ellagic acid moieties appear at 7 and $3 \mathrm{ppm}$, and correspond to $\mathrm{C}-\mathrm{H}$ and $\mathrm{O}-\mathrm{H}$ protons, respectively. A broad signal centered at $5 \mathrm{ppm}$ originates from physisorbed water. Yet another broad resonance at $10 \mathrm{ppm}$ results from $\mathrm{COOH}$ groups, which along with signals from $\mathrm{CH}_{3}$ groups at $\sim 1 \mathrm{ppm}$ indicates the presence of acetic acid remaining in the material after synthesis. A sharp signal at $0.5 \mathrm{ppm}$ can be attributed to hydroxyl groups associated with inorganic building units. The spectrum collected from the sample after adsorption (red trace) reveals increased signal intensity from $\mathrm{H}_{2} \mathrm{O}$ at $4.7 \mathrm{ppm}$, and substantially reduced resonances of acetic acid at 10 and $\sim 1$ ppm. Noteworthy, O-H protons from ellagic acid moieties, as well as those involved in hydroxyl groups, are almost completely gone. Based on these observations, it can be assumed that process of $\mathrm{Ni}$ (II)-ion adsorption on SU-101 can be regarded in terms of an ion exchange with labile protons present in the MOF structure (Figure 5b).

The simultaneous analysis of nickel and cobalt ions is challenging, even by spectrophotometric methods. Herein, we used a method recently reported by Zhou et al. ${ }^{44}$ for the determination of $\mathrm{Ni}$ (II) and $\mathrm{Co}$ (II) in solutions using the UV-vis technique. Our main goal was to evaluate the selectivity of the MOF, SU-101, towards Ni(II) ions over Co(II) in mixed cobaltnickel aqueous solutions. Figures 6 and S9 (in ESI) present the spectra of solutions before and after adsorption (black and red traces respectively), as well as reference solutions containing 4 and $10 \mathrm{mg} \cdot \mathrm{L}^{-1}$ of $\mathrm{Co}(\mathrm{II})$ (blue trace) and 4 or $10 \mathrm{mg} \cdot \mathrm{L}^{-1}$ of $\mathrm{Ni}(\mathrm{II})$ (green trace). In case of $100 \%$ recovery of $\mathrm{Ni}(\mathrm{II})$, we should expect the spectrum after adsorption to overlap with the spectrum of pure $\mathrm{Co}$ (II) solution. By analyzing the spectra, we can observe that the solution after adsorption has a significant decrease in the band intensity in the region from 500 to $450 \mathrm{~nm}$, which corresponds to nickel ions (green trace). The presence of nickel ions broadens the Co(II) spectrum, and narrowing of the band from 500 to $450 \mathrm{~nm}$ indicates the decrease of the initial concentration of nickel ions in solution. Based on the obtained data, we calculated a $\mathrm{Ni}$ (II) recovery of approximately $30 \%$ with respect to the initial solution. Due to the overlap of nickel and cobalt absorption bands in the range from 450 to $400 \mathrm{~nm}$, the slight decrease in the intensity of the maximum absorption correspondent to cobalt ions after adsorption is also related to the decrease of $\mathrm{Ni}$ (II) concentration. There are no significant changes in the $\mathrm{Co}$ (II) spectrum after adsorption that would point out the adsorption of these ions, hence we conclude that there was near-zero adsorption of Co(II). These results confirmed the selectivity of SU-101 towards the separation of Ni(II) from mixed cobalt-nickel solutions.

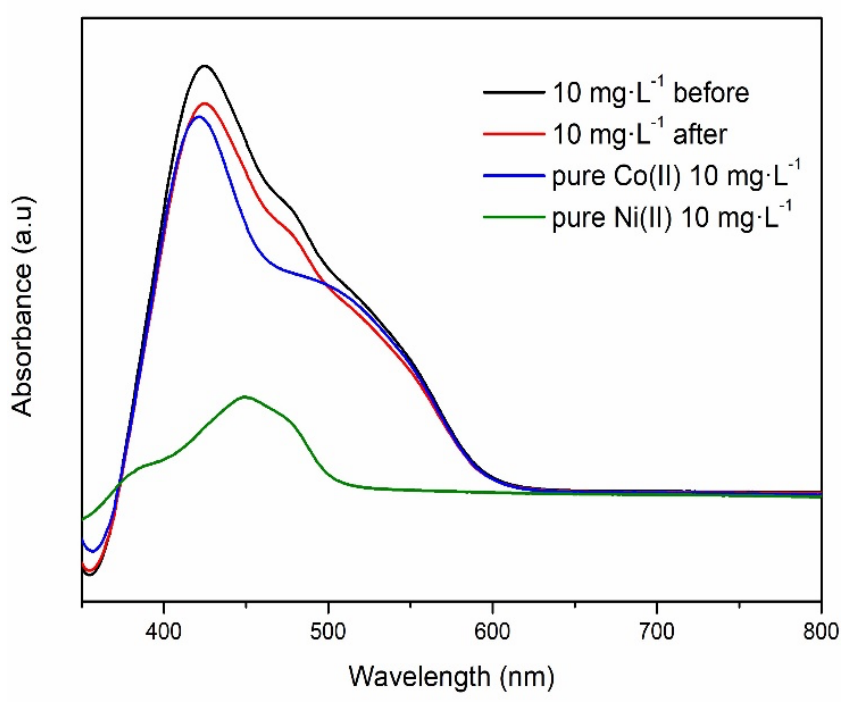

Figure 6. UV-Vis spectra of: initial solution containing 10 $\mathrm{mg} \cdot \mathrm{L}^{-1}$ of $\mathrm{Ni}$ (II) and $\mathrm{Co}$ (II) ions before (black trace) and after (red trace) adsorption, $10 \mathrm{mg} \cdot \mathrm{L}^{-1} \mathrm{Co}$ (II) solution (blue trace) and $10 \mathrm{mg} \cdot \mathrm{L}^{-1} \mathrm{Ni}(\mathrm{II})$ solution (green trace).

\section{CONCLUSIONS}

We have demonstrated the intriguing sorption selectivity of a bioinspired microporous bismuth ellagate metal-organic framework, SU-101, for the separation of nickel ions from mixed cobalt-nickel aqueous solutions. A near-zero sorption of $\mathrm{Co}$ (II) was observed in almost the entire $\mathrm{pH}$ range examined, while for the $\mathrm{Ni}(\mathrm{II})$ adsorption capacity was found to be competitively high (up to 100.9 
$\left.\mathrm{mg} \cdot \mathrm{g}^{-1}\right)$. The evaluation of isotherms showed that the adsorption of nickel ions follows the Freundlich model, pointing out that sorption occurs on a heterogeneous surface. Fast and efficient Ni(II) adsorption (up to 96\%) was obtained, following the pseudo-second order kinetic model, meaning that chemisorption is the main mechanism governing the reaction. Finally, successful separation of $\mathrm{Ni}$ (II) from mixed cobalt-nickel aqueous solutions was performed, reaching approximately $30 \%$ of $\mathrm{Ni}(\mathrm{II})$ recovery and near-zero $\mathrm{Co}$ (II) recovery after $24 \mathrm{~h}$. SU-101 revealed the ability of separating those two ions from aqueous solutions, which provides a great prospect for future applications in spent Li-ion batteries. These results offer a straightforward pathway toward the recycling and separation of valuable metals, while providing a sustainable route for waste valorization in a circular economy. Two significant advantages of using the green MOF are i) the separation of cobalt nickel at room temperature, enabling thus a lower $\mathrm{CO}_{2}$ emission in comparison to pyrometallurgical approaches; and ii) the application of safe chemicals that enable a recycling concept that can be considered as benign by design.

\section{ASSOCIATED CONTENT}

Supporting Information. The supporting information is available free of charge. Figures: $\mathrm{pH}$ of point zero charge, Co(II) adsorption isotherms, fitting of isotherm and kinetic models, UV-Vis spectra of $\mathrm{Ni}$ (II) adsorption from binary solution containing 4 $\mathrm{mg} \cdot \mathrm{L}^{-1}$ of $\mathrm{Ni}(\mathrm{II})$ and $\mathrm{Co}(\mathrm{II})$ each.

\section{AUTHOR INFORMATION}

\section{Corresponding Author}

Adam Slabon - Department of Materials and Environmental Chemistry, Stockholm University, Svante Arrhenius väg 16 C, 10691 Stockholm, Sweden; ORCID: 0000-0002-4452-1831

Email: adam.slabon@mmk.su.se

\section{Authors}

Jędrzej Piątek - Department of Materials and Environmental Chemistry, Stockholm University, Svante Arrhenius väg 16 C, 10691 Stockholm, Sweden; ORCID: 0000-0002-1429-4586

Tetyana M. Budnyak - Department of Materials and Environmental Chemistry, Stockholm University, Svante Arrhenius väg 16C, 10691 Stockholm, Sweden; ORCID: 0000-0003-2112-9308

Bruno Vinicius Manzolli Rodrigues - Department of Materials and Environmental Chemistry, Stockholm University, Svante Arrhenius väg 16C, 10691 Stockholm, Sweden; ORCID: 0000-00020130-8029

Robin Gueret - Department of Materials and Environmental Chemistry, Stockholm University, Svante Arrhenius väg 16C, 106 91 Stockholm, Sweden; ORCID: 0000-0002-7425-5423

Erik Svensson Grape - Department of Materials and Environmental Chemistry, Stockholm University, Svante Arrhenius väg 16C, 10691 Stockholm, Sweden; ORCID: 0000-0002-8956-5897

Aleksander Jaworski - Department of Materials and Environmental Chemistry, Stockholm University, Svante Arrhenius väg 16C, 10691 Stockholm, Sweden; ORCID: 0000-0002-7156-559X
Andrew Ken Inge - Department of Materials and Environmental Chemistry, Stockholm University, Svante Arrhenius väg 16C, 106 91 Stockholm, Sweden; ORCID: 0000-0001-9118-1342

\section{Author Contributions}

All authors have given approval to the final version of the manuscript.

\section{ACKNOWLEDGMENT}

This work was financially supported by the Stiftelsen Olle Engkvists (Project Nr. 198-0329) for financial support. E.S.G. and A.K.I. acknowledge support from the Swedish Foundation for Strategic Research (SSF). J.P. would like to thank Jianhong Chen for help and discussion.

\section{REFERENCES}

(1) Winslow, K. M.; Laux, S. J.; Townsend, T. G. A Review on the Growing Concern and Potential Management Strategies of Waste Lithium-Ion Batteries. Resour. Conserv. Recycl. 2018, 129, 263277.

https://doi.org/https://doi.org/10.1016/j.resconrec.2017.11.001. Wang, H.; Huang, K.; Zhang, Y.; Chen, X.; Jin, W.; Zheng, S.; Zhang, Y.; Li, P. Recovery of Lithium, Nickel, and Cobalt from Spent Lithium-Ion Battery Powders by Selective Ammonia Leaching and an Adsorption Separation System. ACS Sustain. Chem. Eng. 2017, 5 (12), 11489-11495. https://doi.org/10.1021/acssuschemeng.7b02700.

(3) Keersemaker, M. Critical Raw Materials Resilience: Charting a Path towards Greater Security and Sustainability. In Communication from the commission to the European Parliment, the Council, the European Economic and Social Committee and the Committee of the Regions; European Commission: Brussels, 2020; pp 69-82. https://doi.org/10.1007/978-3-030-40268-6_9.

Grant, K.; Goldizen, F. C.; Sly, P. D.; Brune, M. N.; Neira, M.; van den Berg, M.; Norman, R. E. Health Consequences of Exposure to E-Waste: A Systematic Review. Lancet Glob. Heal. 2013, 1 (6), e350-e361. https://doi.org/10.1016/S2214109X(13)70101-3.

(5) de Bruin-Dickason, C.; Budnyk, S.; Piątek, J.; Jenei, I.-Z.; Budnyak, T. M.; Slabon, A. Valorisation of Used Lithium-Ion Batteries into Nanostructured Catalysts for Green Hydrogen from Boranes. Mater. Adv. 2020, 1 (7), $2279-2285$. https://doi.org/10.1039/D0MA00372G.

(6) Yin, H.; Xing, P. Pyrometallurgical Routes for the Recycling of Spent Lithium-Ion Batteries BT - Recycling of Spent LithiumIon Batteries: Processing Methods and Environmental Impacts; An, L., Ed.; Springer International Publishing: Cham, 2019; pp 57-83. https://doi.org/10.1007/978-3-030-31834-5_3.

(7) Zheng, X.; Zhu, Z.; Lin, X.; Zhang, Y.; He, Y.; Caō, H.; Sun, Z. A Mini-Review on Metal Recycling from Spent Lithium Ion Batteries. Engineering 2018, 4 (3), 361-370. https://doi.org/10.1016/j.eng.2018.05.018.

(8) Chen, W. S.; Ho, H. J. Recovery of Valuable Metals from Lithium-Ion Batteries NMC Cathode Waste Materials by Hydrometallurgical Methods. Metals (Basel). 2018, 8 (5), 321.

(9) Tait, B. K. Cobalt-Nickel Separation: The Extraction of Cobalt(II) and Nickel(II) by Cyanex 301, Cyanex 302 and Cyanex 272. Hydrometallurgy 1993, 32 (3), 365-372. https://doi.org/10.1016/0304-386X(93)90047-H.

(10) Online, V. A.; Wellens, S.; Thijs, B.; Mo, C.; Binnemans, K. With Two Mutually Immiscible Ionic Liquids †. 2013, 9663-9669. https://doi.org/10.1039/c3cp50819f.

(11) Joulié, M.; Laucournet, R.; Billy, E. Hydrometallurgical Process for the Recovery of High Value Metals from Spent Lithium Nickel Cobalt Aluminum Oxide Based Lithium-Ion Batteries. $J$. Power Sources 2014, 247, 551-555. https://doi.org/10.1016/j.jpowsour.2013.08.128.

(12) Chen, X.; Zhou, T.; Kong, J.; Fang, H.; Chen, Y. Separation and Recovery of Metal Values from Leach Liquor of Waste Lithium Nickel Cobalt Manganese Oxide Based Cathodes. Sep. Purif. Technol. 2015, 141, 76-83. https://doi.org/10.1016/j.seppur.2014.11.039.

(13) Grinstead, R. R. Selective Absorption of Copper, Nickel, Cobalt and Other Transition Metal Ions from Sulfuric Acid Solutions 
with the Chelating Ion Exchange Resin Xfs 4195. Hydrometallurgy 1984, 12, 387-400.

(14) Botelho Junior, A. B.; Dreisinger, D. B.; Espinosa, D. C. R. A Review of Nickel, Copper, and Cobalt Recovery by Chelating Ion Exchange Resins from Mining Processes and Mining Tailings. Mining, Metall. Explor. 2019, 36 (1), 199-213. https://doi.org/10.1007/s42461-018-0016-8.

(15) Anastas, P.; Eghbali, N. Green Chemistry: Principles and Practice. Chem. Soc. Rev. 2010, 39 (1), 301-312. https://doi.org/10.1039/b918763b.

(16) Anastas, P. T.; Warner, J. C. Green Chemistry: Theory and Practice; New York: Oxford University Press.: New York, 1998.

(17) Dabrowski, A. Adsorption To from Theory to Practice \&. Adv. Colloid Interface Sci. 2001, 93, 135-224.

(18) Ubando, A. T.; Africa, A. D. M.; Maniquiz-Redillas, M. C.; Culaba, A. B.; Chen, W. H.; Chang, J. S. Microalgal Biosorption of Heavy Metals: A Comprehensive Bibliometric Review. J. Hazard. Mater. 2021, 402 (July 2020), 123431. https://doi.org/10.1016/j.jhazmat.2020.123431.

(19) Budnyak, T. M.; Aminzadeh, S.; Pylypchuk, I. V.; Sternik, D.; Tertykh, V. A.; Lindström, M. E.; Sevastyanova, O. Methylene Blue Dye Sorption by Hybrid Materials from Technical Lignins. J. Environ. Chem. Eng. 2018, 6 (4), 4997-5007. https://doi.org/10.1016/j.jece.2018.07.041.

(20) Bergfreund, J.; Bertsch, P.; Fischer, P. Adsorption of Proteins to Fluid Interfaces: Role of the Hydrophobic Subphase. J. Colloid Interface Sci. $\quad$ 2021, $\quad 584, \quad 411-417$. https://doi.org/10.1016/j.jcis.2020.09.118.

(21) Piątek, J.; Afyon, S.; Budnyak, T. M.; Budnyk, S.; Sipponen, M. H.; Slabon, A. Sustainable Li-Ion Batteries: Chemistry and Recycling. Adv. Energy Mater. 2020, 2003456. https://doi.org/10.1002/aenm.202003456.

(22) Prado, A. G. S.; Arakaki, L. N. H.; Airoldi, C. Adsorption and Separation of Cations on Silica Gel Chemically Modified by Homogeneous and Heterogeneous Routes with the Ethylenimine Anchored on Thiol Modified Silica Gel. Green Chem. 2002, 4 (1), 42-46. https://doi.org/10.1039/b108749e.

(23) Piątek, J.; de Bruin-Dickason, C. N.; Jaworski, A.; Chen, J.; Budnyak, T.; Slabon, A. Glycine-Functionalized Silica as Sorbent for Cobalt(II) and Nickel(II) Recovery. Appl. Surf. Sci. 2020, 530, 147299.

(24) Ferri, M.; Campisi, S.; Gervasini, A. Nickel and Cobalt Adsorption on Hydroxyapatite: A Study for the de-Metalation of Electronic Industrial Wastewaters. Adsorption 2019, 0 (0), 0. https://doi.org/10.1007/s10450-019-00066-w.

(25) Budnyak, T. M.; Modersitzki, S.; Pylypchuk, I. V.; Piątek, J.; Jaworski, A.; Sevastyanova, O.; Lindström, M. E.; Slabon, A. Tailored Hydrophobic/Hydrophilic Lignin Coatings on Mesoporous Silica for Sustainable Cobalt(II) Recycling. ACS Sustain. Chem. $\quad$ Eng. 2020. https://doi.org/10.1021/acssuschemeng.0c05696.

(26) Wu, S.; Liu, J.; Wang, H.; Yan, H. A Review of Performance Optimization of MOF-Derived Metal Oxide as Electrode Materials for Supercapacitors. Int. J. Energy Res. 2019, 43 (2), 697-716. https://doi.org/10.1002/er.4232.

(27) Gangu, K. K.; Maddila, S.; Mukkamala, S. B.; Jonnalagadda, S B. Characteristics of MOF, MWCNT and Graphene Containing Materials for Hydrogen Storage: A Review. J. Energy Chem. 2019 , 30 ,

$132-144$ https://doi.org/10.1016/j.jechem.2018.04.012

(28) Goetjen, T. A.; Liu, J.; Wu, Y.; Sui, J.; Zhang, X.; Hupp, J. T.; Farha, O. K. Metal-Organic Framework (MOF) Materials as Polymerization Catalysts: A Review and Recent Advances. Chem. Commun. 2020, 56 (72), 10409-10418. https://doi.org/10.1039/d0cc03790g.

(29) Ren, J.; Langmi, H. W.; North, B. C.; Mathe, M. Review on Processing of Metal-Organic Framework (MOF) Materials towards System Integration for Hydrogen Storage. Int. J. Energy Res. 2015, 39, 607-620. https://doi.org/10.1002/er.3255.

(30) Xuan, W.; Zhu, C.; Liu, Y.; Cui, Y. Mesoporous Metal-Organic Framework Materials. Chem. Soc. Rev. 2012, 41 (5), 1677-1695. https://doi.org/10.1039/c1cs15196g.

(31) Zhu, Q. L.; Xu, Q. Metal-Organic Framework Composites. Chem. Soc. Rev. 2014, $43 \quad$ (16), 5468-5512. https://doi.org/10.1039/c3cs60472a.

(32) Bagi, S.; Wright, A. M.; Oppenheim, J.; Dinca, M.; Rom, Y. Accelerated Synthesis of a Ni $2 \mathrm{Cl} 2$ (BTDD) Metal - Organic Framework in a Continuous Flow Reactor for Atmospheric Water
Capture.

2021,

Xu, W.; Yaghi, O. M. Metal-Organic Frameworks for Water Harvesting from Air, Anywhere, Anytime. ACS Cent. Sci. 2020, 6 (8), 1348-1354. https://doi.org/10.1021/acscentsci.0c00678.

Huang, J.; Huang, D.; Zeng, F.; Ma, L.; Wang, Z. Photocatalytic MOF Fibrous Membranes for Cyclic Adsorption and Degradation of Dyes. J. Mater. Sci. 2021, 56 (4), 3127-3139. https://doi.org/10.1007/s10853-020-05473-x.

Ibarra, I. A.; Lin, X.; Yang, S.; Blake, A. J.; Walker, G. S.; Barnett, S. A.; Allan, D. R.; Champness, N. R.; Hubberstey, P.; Schröder, M. Structures and H2 Adsorption Properties of Porous Scandium Metal-Organic Frameworks. Chem. - A Eur. J. 2010, 16 (46), 13671-13679. https://doi.org/10.1002/chem.201000926. Jaffe, A.; Ziebel, M. E.; Halat, D. M.; Biggins, N.; Murphy, R. A.; Chakarawet, K.; Reimer, J. A.; Long, J. R. Selective, HighTemperature O2Adsorption in Chemically Reduced, RedoxActive Iron-Pyrazolate Metal-Organic Frameworks. J. Am. Chem. Soc. 2020, 142 (34), 14627-14637. https://doi.org/10.1021/jacs.0c06570.

Ghanbari, T.; Abnisa, F.; Wan Daud, W. M. A. A Review on Production of Metal Organic Frameworks (MOF) for $\mathrm{CO} 2$ Adsorption. Sci. Total Environ. 2020, 707, 135090. https://doi.org/10.1016/j.scitotenv.2019.135090.

Xu, G. R.; An, Z. H.; Xu, K.; Liu, Q.; Das, R.; Zhao, H. L. Metal Organic Framework (MOF)-Based Micro/Nanoscaled Materials for Heavy Metal Ions Removal: The Cutting-Edge Study on Designs, Synthesis, and Applications. Coord. Chem. Rev. 2021, 427. https://doi.org/10.1016/j.ccr.2020.213554.

Grape, E. S.; Gabriel Flores, J.; Hidalgo, T.; Martínez-Ahumada, E.; Gutierrez-Alejandre, A.; Hautier, A.; Williams, D. R.; O'Keeffe, M.; Ohrström, L.; Willhammar, T.; Horcajada, P.; Ibarra, I. A.; Ken Inge, A. A Robust and Biocompatible Bismuth Ellagate MOF Synthesized under Green Ambient Conditions. $J$. Am. Chem. Soc. 2020, 142 (39), 16795-16804. https://doi.org/10.1021/jacs.0c07525.

Marchenko, Z. Photometric Determination of Elements; MIR, 1971.

Ayawei, N.; Ebelegi, A. N.; Wankasi, D. Modelling and Interpretation of Adsorption Isotherms. J. Chem. 2017, 2017, 111.

Simonin, J. P. On the Comparison of Pseudo-First Order and Pseudo-Second Order Rate Laws in the Modeling of Adsorption Kinetics. Chem. Eng. J. 2016, 300, 254-263. https://doi.org/10.1016/j.cej.2016.04.079.

Namdeo, M.; Bajpai, S. K. Chitosan-Magnetite Nanocomposites (CMNs) as Magnetic Carrier Particles for Removal of Fe(III) from Aqueous Solutions. Colloids Surfaces A Physicochem. Eng. Asp. 2008, $320 \quad$ (1-3), 161-168. https://doi.org/10.1016/j.colsurfa.2008.01.053.

Zhou, F.; Li, C.; Zhu, H.; Li, Y. A Novel Method for Simultaneous Determination of Zinc, Nickel, Cobalt and Copper Based on UV-Vis Spectrometry. Optik (Stuttg). 2019, 182 (December 2018), 58-64. https://doi.org/10.1016/j.ijleo.2018.12.159.

Kervern, G.; Pintacuda, G.; Emsley, L. Fast Adiabatic Pulses for Solid-State NMR of Paramagnetic Systems. Chem. Phys. Lett. 2007, 435 (1-3), 157-162. https://doi.org/10.1016/j.cplett.2006.12.056.

Hwang, T. L.; Van Zijl, P. C. M.; Garwood, M. Fast Broadband Inversion by Adiabatic Pulses. J. Magn. Reson. 1998, 133 (1), 200-203. https://doi.org/10.1006/jmre.1998.1441.

Kołodyńska, D.; Gęca, M.; Pylypchuk, I. V.; Hubicki, Z. Development of New Effective Sorbents Based on Nanomagnetite. Nanoscale Res. Lett. 2016, 11 (1), 152-161. https://doi.org/10.1186/s11671-016-1371-3.

Anoop Krishnan, K.; Sreejalekshmi, K. G.; Baiju, R. S. Nickel(II) Adsorption onto Biomass Based Activated Carbon Obtained from Sugarcane Bagasse Pith. Bioresour. Technol. 2011, 102 (22), 10239-10247. https://doi.org/10.1016/j.biortech.2011.08.069.

Kalyani, S.; Srinivasa Rao, P.; Krishnaiah, A. Removal of Nickel (II) from Aqueous Solutions Using Marine Macroalgae as the Sorbing Biomass. Chemosphere 2004, 57 (9), 1225-1229. https://doi.org/10.1016/j.chemosphere.2004.08.057. 
